Check for updates

Cite this: RSC Adv., 2021, 11, 26049

Received 14th June 2021

Accepted 22nd July 2021

DOI: 10.1039/d1ra04595d

rsc.li/rsc-advances

\title{
One-pot synthesis for gradient copolymers via concurrent tandem living radical polymerization: mild and selective transesterification of methyl acrylate through $\left.\mathrm{Al}_{(\mathrm{acac}}\right)_{3}$ with common alcohols $\uparrow$
}

\author{
Tam Thi-Thanh Huynh, (DD ab Si Eun Kim, (DD a Soon Cheon Kim, (ID a Jin Chul Kim, (D) ${ }^{a}$ \\ Young II Park, (D) ${ }^{a}$ Ji-Eun Jeong, (D) ${ }^{a}$ Hyeonuk Yeo (D) ${ }^{* b c}$ and Sang-Ho Lee (D) *a
}

\begin{abstract}
A series of gradient copolymers were synthesized by the ruthenium-catalyzed living radical polymerization (LRP) of methyl acrylate (MA) and aliphatic alcohols using aluminum acetylacetonate $\mathrm{Al}(\mathrm{acac})_{3}$. In this polymerization system, $\mathrm{Al}(\mathrm{acac})_{3}$ was successfully used not only as an additive for the Ru-catalyzed LRP but also as a catalyst for the selective transesterification of an unsaturated ester monomer in mild conditions in a process known as concurrent tandem living radical polymerization. The resulting MAbased gradient copolymers showed well-controlled molecular weight and distribution in a one-pot reaction and exhibited a well-controlled gradient sequence in their polymer chain. Control of transesterification and the metal-catalyzed living radical polymerization (Mt-LRP) rate varied depending on the concentration of the $\mathrm{Al}(\mathrm{acac})_{3}$ and the structure of varying alcohols, which were confirmed by ${ }^{1} \mathrm{H}$ NMR, SEC, and DSC analysis. In particular, this research opens a new synthetic methodology for preparing acrylate-based gradient copolymers via concurrent tandem LRP not limited to the synthesis of methyl methacrylate types of gradient copolymers.
\end{abstract}

\section{Introduction}

After the first proposal for the concept of a "gradient copolymer" in $1977,{ }^{1}$ the studies of their synthesis and properties have attracted significant interest in related fields. Gradient copolymers possess highly interesting molecular structures, in which a progressive transition of repeating components continues along the development of a polymer chain. Owing to the continuously changing structural nature along the chains, the gradient copolymers have unique properties which lead to less intra- and interchain repulsion, unlike block copolymers. These characteristics make them usable in a number of applications such as in thermoplastic elastomers, ${ }^{2}$ nanostructured carbons, ${ }^{3}$ multishape memory materials, ${ }^{4}$ dispersants, functionalized surfaces, bio-medical materials, ${ }^{\mathbf{5 , 6}}$ and vibration damping materials. $^{7}$

In the past decades, the living radical polymerization (LRP) method has been developed as a powerful tool which has

${ }^{a}$ Center for Advanced Specialty Chemicals, Korea Research Institute of Chemical Technology, Ulsan 44412, Republic of Korea

${ }^{b}$ Department of Science Education, Kyungpook National University, Daegu, 41566, Republic of Korea

${ }^{c}$ Department of Chemistry Education, Department of Pharmacy, Kyungpook National University, Daegu, 41566, Republic of Korea. E-mail: slee@krict.re.kr; yeo@knu.ac.kr $\dagger$ Electronic supplementary information (ESI) available. See DOI: 10.1039/d1ra04595d significantly impacted the field of polymer materials synthesis. Specifically, nitroxide-mediated radical polymerization (NMP), ${ }^{\mathbf{8}, 9}$ reversible addition-fragmentation chain transfer radical polymerization (RAFT), ${ }^{\mathbf{1 0}-12}$ and metal-catalyzed living radical polymerization (Mt-LRP) ${ }^{13-16}$ have been used to synthesize gradient copolymers. Among these, Mt-LRP is known as a prominent method to synthesis various polymers with tailoring polydispersity and molecular weight distribution such as homopolymers, block copolymers, random copolymers, and star polymers. ${ }^{17-19}$ In addition, Mt-LRP systems have attracted much attention based on high controllability in the addition of metal alkoxides, which not only control the molecular weights but also increase the polymerization rate.

Over the past few years, Sawamoto and Terashima have reported a new synthetic strategy for the preparation of gradient copolymers in one-pot synthesis using a concurrent catalysis system. ${ }^{20-22}$ This polymerization system, known as concurrent tandem LRP, is a combination of the transesterification of an unsaturated ester monomer with alcohols using a metal alkoxide such as $\mathrm{Al}(\mathrm{O} i \text {-Pr })_{3}$ or $\mathrm{Ti}(\mathrm{O} i-\mathrm{Pr})_{4}$ and ruthenium $(\mathrm{Ru})$ catalyzed LRP in conjunction with a metal alkoxide as a cocatalyst, and has led to well-defined polymer structures via resulting smooth redox reactions. ${ }^{13}$ Thereby, it induces selective transesterification for only the methyl methacrylate monomer (MMA) type monomer with various alcohols (not polymer chain in propagation), which allows for well-controlled gradient 


\section{Concurrent Tandem LRP}

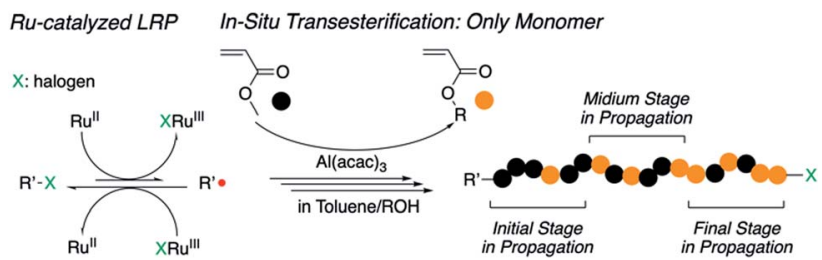

Scheme 1 Concurrent tandem living radical polymerization for acrylate-based gradient copolymer synthesis.

sequences in the polymer chain. However, this strategy is not perfectly applicable to the acrylate type monomer owing to the high reactivity of metal alkoxide, which led to partial transesterification of the polymer chains.

Thus, in this work, we report the concurrent tandem LRP used to prepare an acrylate-based gradient copolymer using aluminum $(\mathrm{Al})$ acetylacetonate $\left(\mathrm{Al}(\mathrm{acac})_{3}\right)$. The $\mathrm{Al}(\mathrm{acac})_{3}$ is also an effective catalyst for transesterification and has relatively lower Lewis acidity than other metal alkoxides. ${ }^{21}$ In addition, it can be used as an additive to Ru-catalyzed LRP. ${ }^{13}$ These two roles of $\mathrm{Al}(\mathrm{acac})_{3}$ for each reaction are successfully synchronized in the concurrent tandem LRP to create an acrylate-based gradient copolymer carrying a well-controlled gradient sequence in the polymer chain in a one-pot synthesis through the gradual transesterification of the acrylate monomer (Scheme 1). Note that our focus is to expand the monomer scope in concurrent tandem LRP as well as synthesis of well-defined gradient copolymers.

\section{Experimental section}

\section{Materials}

Methyl acrylate (MA, Sigma-Aldrich, 99\%) was purified before use by a neutral aluminum oxide column to remove the inhibitor and was kept at $0{ }^{\circ} \mathrm{C} . \mathrm{Ru}(\mathrm{Cp} *) \mathrm{Cl}\left(\mathrm{PPh}_{3}\right)_{2}$ (Sigma-Aldrich), tetralin (Sigma-Aldrich, 99\%), and ethyl 2-bromopropionate (EBP, Sigma-Aldrich, purity $>98 \%$ ) were used as received and kept at $0{ }^{\circ} \mathrm{C}$. $\mathrm{Al}(\text { acac) })_{3}$ (Sigma-Aldrich, purity $>97 \%$ ), ethanol (Sigma-Aldrich, anhydrous, $\geq 99.5 \%$ ), iso-propanol (SigmaAldrich, anhydrous, $\geq 99.5 \%$ ), octanol (Sigma-Aldrich, ACS reagent, $\geq 99 \%$ ), and benzyl alcohol (Sigma-Aldrich, anhydrous, 99.8\%) were degassed before use. Toluene (Sigma-Aldrich; $\geq 99.9 \%$ ) was purified by being passed through purification columns (JCM, JCM-3SPS-SA-6) and bubbled with dry nitrogen gas for more than 15 min immediately before use. Molecular sieves $4 \AA$ (MS $4 \AA$ ) were dried under reduced pressure at $300{ }^{\circ} \mathrm{C}$ by a heat gun before use.

\section{Measurements}

The $M_{\mathrm{n}}$ and $M_{\mathrm{w}} / M_{\mathrm{n}}$ of polymers were measured by SEC at $40{ }^{\circ} \mathrm{C}$ using tetrahydrofuran (THF) as an eluent. For the THF-SEC, three polystyrene-gel columns [GP LF-404 (from Shodex); pore size, $3000 \AA$ A; $4.6 \mathrm{~mm}$ i. d. $\times 250 \mathrm{~mm}$ ]; were connected to a PU4180 pump, a RI-4030 refractive-index detector, and a UV-4075 ultraviolet detector (JASCO) and the flow rate was set to 0.3
$\mathrm{mL} \min ^{-1}$. The columns were calibrated against 13 standard poly(methyl methacrylate) samples (Agilent Technologies; $\mathrm{Mp}=$ 2380-1120 000). Proton nuclear magnetic resonance ( ${ }^{1} \mathrm{H}$ NMR) was recorded on a Bruker Ultrashield spectrometer operating at $300 \mathrm{MHz}$. The thermal properties of the gradient copolymer were determined using differential scanning calorimetry (DSC, TA 3000).

\section{$\mathrm{Al}(\mathrm{acac})_{3}$-catalyzed transesterification of MA with varying alcohols}

Transesterification was conducted using the syringe technique under dry Ar in baked glass tubes equipped with a three-way stopcock. A typical procedure for the MA with varying alcohols is given. For example, MS $4 \AA\left(0.33 \mathrm{~g} \mathrm{~mL}^{-1}\right)$ was added into a tube and dried in vacuo. In another $30 \mathrm{~mL}$ tube, toluene $(1.46$ $\mathrm{mL})$, ethanol $(1.96 \mathrm{~mL})$, tetralin $(0.14 \mathrm{~mL})$, a $0.2 \mathrm{M}$ toluene solution of $\mathrm{Al}(\mathrm{acac})_{3}(0.5 \mathrm{~mL}, 0.1 \mathrm{mmol})$, and $\mathrm{MA}(10 \mathrm{mmol}, 0.95$ $\mathrm{mL}$ ) were added in the same order at room temperature. The solution was added into to the glass tube containing MS 4 A. The total volume of the reaction mixture was controlled to $5 \mathrm{~mL}$. Then, the mixture was immediately moved in an oil bath that was at $80{ }^{\circ} \mathrm{C}$. Aliquots from the reaction solution were withdrawn in predetermined intervals using a syringe and the subsequent reaction was terminated by cooling to $-78{ }^{\circ} \mathrm{C}$. The conversion of transesterification was determined using ${ }^{1} \mathrm{H}$ NMR spectroscopy.

\section{Metal-catalyzed living radical polymerization of MA using $\mathrm{Al}(\text { acac })_{3}$ as an additive}

The Mt-LRP was conducted using a similar procedure described above and a typical procedure for MA with varying alcohols is given. $\mathrm{Ru}\left(\mathrm{Cp}^{*}\right) \mathrm{Cl}\left(\mathrm{PPh}_{3}\right)_{2}(0.0398 \mathrm{~g}, 0.05 \mathrm{mmol})$, toluene $3.66 \mathrm{~mL}$, tetralin $(0.14 \mathrm{~mL}), \mathrm{MA}(0.95 \mathrm{~mL}, 10 \mathrm{mmol})$, and EBP $(0.25 \mathrm{~mL}$ of $0.4 \mathrm{M}$ in toluene, $0.1 \mathrm{~mol}$ ) were sequentially added into a $30 \mathrm{~mL}$ glass tube. The total volume of the reaction mixture was controlled to $5 \mathrm{~mL}$ and immediately heated to $80{ }^{\circ} \mathrm{C}$. Aliquots from the reaction solution were withdrawn in predetermined intervals using a syringe, and the subsequent reaction was terminated by cooling to $-78{ }^{\circ} \mathrm{C}$. Total monomer conversion was determined using ${ }^{1} \mathrm{H}$ NMR spectroscopy using an internal standard.

\section{Gradient copolymer synthesis via tandem catalyst}

The gradient copolymerization with tandem catalyst was carried out by a similar procedure described above and a typical procedure for MA with varying alcohols is given. For example, MS $4 \AA$ ̊ $\left(0.33 \mathrm{~g} \mathrm{~mL}^{-1}\right)$ was added into a tube and dried in vacuo. In another tube, $\mathrm{Ru}\left(\mathrm{Cp}^{*}\right) \mathrm{Cl}\left(\mathrm{PPh}_{3}\right)_{2}(0.0398 \mathrm{~g}, 0.05 \mathrm{mmol})$, toluene $(1.33 \mathrm{~mL})$, tetralin $(0.14 \mathrm{~mL}), \mathrm{Al}(\mathrm{acac})_{3}(0.5 \mathrm{~mL}$ of $0.2 \mathrm{M}$ in toluene, $0.1 \mathrm{mmol})$, MA $(0.95 \mathrm{~mL}, 10 \mathrm{mmol})$, EtOH $(1.83 \mathrm{~mL})$, and EBP $(0.25 \mathrm{~mL}$ of $0.4 \mathrm{M}$ in toluene, $0.1 \mathrm{mmol})$ were sequentially added. The solution was added into to the glass tube containing MS 4 A and the total volume was controlled to 5 $\mathrm{mL}$. The mixture was immediately heated to $80{ }^{\circ} \mathrm{C}$ and aliquots from the reaction solution were withdrawn in predetermined intervals using a syringe. The polymerization was terminated by 
cooling to $-78{ }^{\circ} \mathrm{C}$. Total monomer conversion and monomer compositions in polymer solution were determined using ${ }^{1} \mathrm{H}$ NMR spectroscopy using an internal standard. The products in each aliquot were obtained upon solvent removal using rotary evaporation and further dried under reduced pressure. The cumulative $\left(F_{\text {cum }}\right)$ contents and instantaneous $\left(F_{\text {inst }}\right)$ contents were calculated from the repeat-unit composition of resulting polymers, which was determined using ${ }^{1} \mathrm{H}$ NMR spectroscopy.

\section{$\mathrm{Al}(\mathrm{acac})_{3}$-catalyzed transesterification of poly(methyl acrylate) (PMA) with ethanol}

The transesterification of $\mathrm{PMA}_{100}$ was conducted using a similar

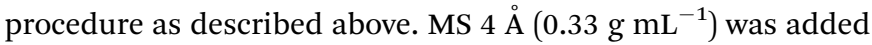
into a tube and dried in vacuo. In another tube, $0.88 \mathrm{~g}$ of $\mathrm{PMA}_{100}$ $\left(M_{\mathrm{n}, \mathrm{SEC}}=10200, M_{\mathrm{w}} / M_{\mathrm{n}}=1.16, \mathrm{DP}_{\mathrm{n}, \mathrm{NMR}}=100\right)$, toluene $(1.93$ $\mathrm{mL})$, EtOH $(2.43 \mathrm{~mL})$, tetralin $(0.14 \mathrm{~mL})$, and a $0.2 \mathrm{M}$ toluene solution of $\mathrm{Al}(\mathrm{acac})_{3}(0.5 \mathrm{~mL}, 0.1 \mathrm{mmol})$ were sequentially added. The solution was added into to the glass tube containing MS $4 \AA$ and the total volume was controlled to $5 \mathrm{~mL}$. The mixture was immediately heated to $80{ }^{\circ} \mathrm{C}$ and aliquots from the reaction solution were withdrawn in predetermined intervals using a syringe. The reaction was terminated by cooling to $-78{ }^{\circ} \mathrm{C}$ and the products in each aliquot were obtained upon solvent removal using rotary evaporation. The product was further dried under reduced pressure and the structural change was tracked using ${ }^{1} \mathrm{H}$ NMR spectroscopy.

\section{Results and discussion}

\section{Al(acac) $)_{3}$-catalyzed transesterification of MA and PMA with alcohols}

To obtain the well-controlled gradual composition of the monomer used in the gradient copolymer chain by in situ transesterification, the following factors had to be satisfied: (i) transesterification should have selectively occurred to the monomer only (not the polymer); (ii) the cooperative catalytic system was required for the Ru-catalyzed LRP and transesterification; (iii) the propagation must have been living without termination and chain transfer. ${ }^{\mathbf{2 0 , 2 2}}$ Thus, $\mathrm{Al}(\mathrm{acac})_{3}$ was used to the transesterification of MA and PMA in alcohol/toluene $(1 / 1, \mathrm{v} /$ v) at $80{ }^{\circ} \mathrm{C}$ (Fig. 1). The transesterification of MA was observed for
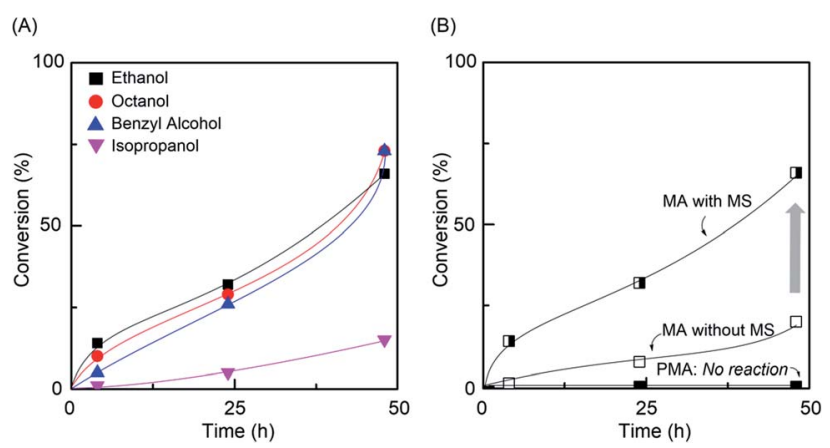

Fig. $1 \mathrm{Al}(\mathrm{acac})_{3}$-catalyzed transesterification of (A) MA with varying alcohols and (B) PMA with ethanol in toluene at $80^{\circ} \mathrm{C}:[\mathrm{MA}]_{0}=2.0 \mathrm{M}$ or $\left[P M A\left(D_{n, N M R}=100\right)\right]_{0}=20 \mathrm{mM} ;\left[A l(\operatorname{acac})_{3}\right]_{0}=20 \mathrm{mM}$ in toluene/ alcohols $(1 / 1, v / v)$.
Table 1 Ru-catalyzed LRP of MA with various initiators in conjunction with $\left.\mathrm{Al}_{(\mathrm{acac}}\right)_{3}$ as an additive ${ }^{a}$

\begin{tabular}{lllllll}
\hline Entry & Initiator & Catalyst & Time (h) & Conv. $^{b}(\%)$ & $M_{\mathrm{n}}{ }^{c}$ & $M_{\mathrm{w}} / M_{\mathrm{n}}{ }^{c}$ \\
\hline 1 & EBP & RuCp* & 48 & 78 & 4900 & 1.09 \\
2 & EBP & RuPPh & 96 & 65 & 6200 & 1.35 \\
3 & EBP & RuInd & 24 & 35 & 1200 & 2.57 \\
4 & EBiB & RuPPh $_{3}$ & 96 & 32 & 1000 & 1.58 \\
5 & EBiB & RuInd & 96 & 54 & 4300 & 1.67 \\
6 & ECPA & RuPPh & 96 & 53 & 4400 & 1.31 \\
7 & ECPA & RuInd & 96 & 47 & 6800 & 1.92
\end{tabular}

${ }^{a}[\mathrm{MA}]_{0}=2.0 \mathrm{M} ;[\text { initiator }]_{0}=20 \mathrm{mM} ;[\mathrm{Ru}]_{0}=2.0 \mathrm{mM} ;\left[\mathrm{Al}(\text { acac })_{3}\right]_{0}=$ $10 \mathrm{mM}$ in toluene at $80{ }^{\circ} \mathrm{C} .{ }^{b}$ Conversion was determined by ${ }^{1} \mathrm{H}$ NMR. ${ }^{c}$ Measured by size-exclusion chromatography calibrated with PMMA standards in THF $\left(40^{\circ} \mathrm{C}\right.$, flow rate $\left.0.3 \mathrm{~mL} \mathrm{~min}^{-1}\right)$.

different alcohols, but PMA $\left(M_{\mathrm{n}, \mathrm{SEC}}=10200, M_{\mathrm{w}} / M_{\mathrm{n}}=1.16\right.$, $\left.\mathrm{DP}_{\mathrm{n}, \mathrm{NMR}}=100\right)$ did not participate in the transesterification reaction, indicating that the selective transesterification occurred (Fig. S1 and S2 $\dagger$ ). Particularly, primary alcohols showed higher transesterification efficiency than secondary alcohol due to its higher reactivity. In addition, in molecular sieve (MS, $4 \AA$ ) , the transesterification efficiency was enhanced by removing of the methanol molecule that formed during the reaction. ${ }^{23}$

\section{Effect of $\mathrm{Al}(\text { acac })_{3}$ as an additive for Ru-catalyzed LRP}

The polymerization of MA was performed with varying initiators such as EBP, EBiB, and ECPA. Three Ru complexes, Ru(Cp*) $\mathrm{Cl}\left(\mathrm{PPh}_{3}\right)_{2} \quad\left(\mathrm{RuCp}^{*}\right){ }^{24} \mathrm{RuCl}_{2}\left(\mathrm{PPh}_{3}\right)_{2} \quad(\mathrm{RuPPh}){ }^{25}$ and $\mathrm{Ru}($ Ind) $\mathrm{Cl}\left(\mathrm{PPh}_{3}\right)_{2}(\mathrm{RuInd})^{26}$ were examined as catalysts with $\mathrm{Al}(\text { acac })_{3}$ as
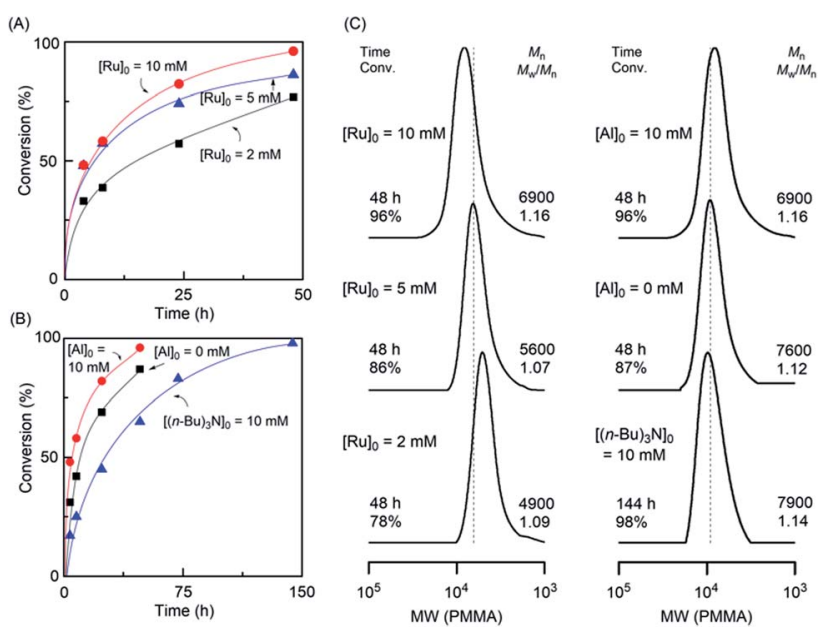

Fig. 2 Homopolymerization of methyl acrylate with (A) varying ratios of $\mathrm{Ru}$ catalyst at a fixed ratio of Al cocatalyst, (B) varying cocatalyst concentration at a fixed ratio of Ru catalyst, and (C) corresponding SEC traces of the respective polymerizations with (left) the varying ratio of Ru catalyst at a fixed ratio of Al cocatalyst, and (right) varying cocatalyst at a fixed ratio of Ru catalyst. Dotted lines are included to aid the visual comparison. Reaction conditions: $[\mathrm{MA}]_{0}=2.0 \mathrm{M}$; $[\mathrm{EBP}]_{0}=20 \mathrm{mM}$; $\left[\mathrm{Ru}\left(\mathrm{Cp} * \mathrm{Cl}\left(\mathrm{PPh}_{3}\right)_{2}\right]_{0}=2-10 \mathrm{mM} \text {; [additive }\right]_{0}=0-10 \mathrm{mM}$ in toluene at $80{ }^{\circ} \mathrm{C}$. 
(A) $[\mathrm{Al}]_{0}=10 \mathrm{mM}$
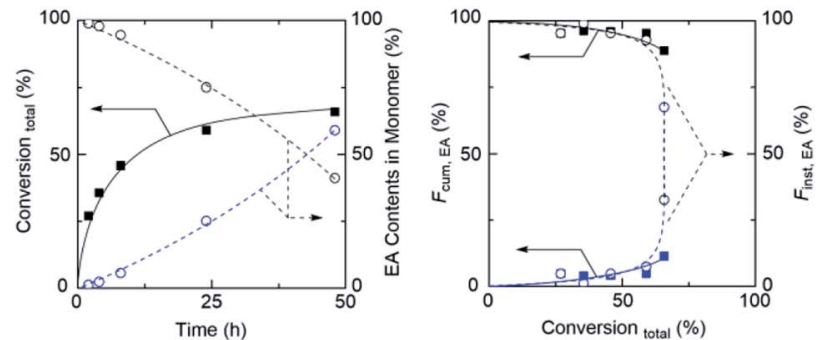

(B) $[\mathrm{Al}]_{0}=20 \mathrm{mM}$
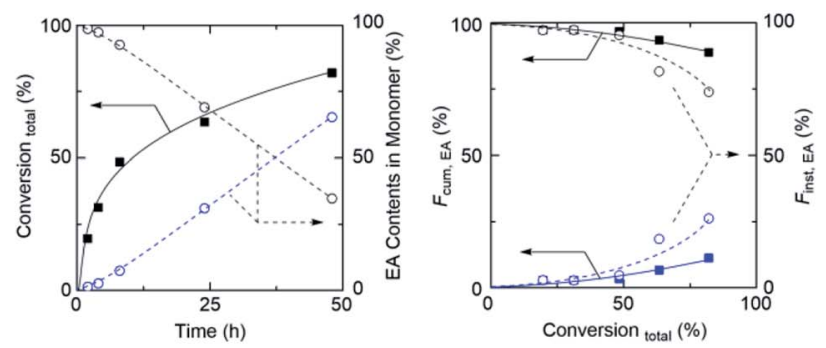

(C) $[\mathrm{Al}]_{0}=40 \mathrm{mM}$
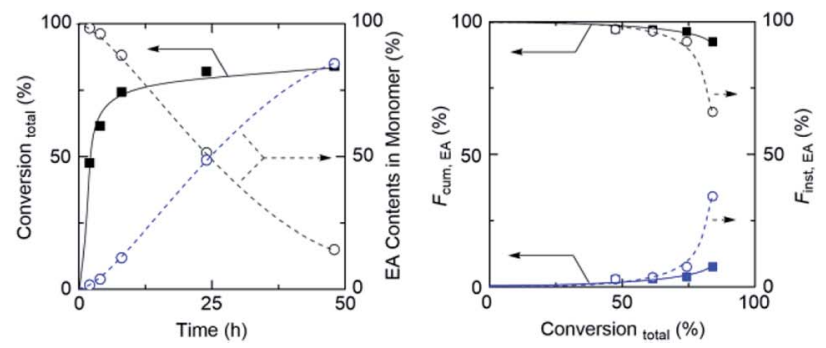

Fig. 3 Effect of $\mathrm{Al}(\mathrm{acac})_{3}$ concentration on the synthesis of MA/EA gradient copolymer by concurrent tandem LRP: total conversion and EA contents in polymerization solution (left) and cumulative ( $\left.F_{\text {cum,EA }}\right)$ or instantaneous $\left(F_{\text {inst,EA }}\right)$ contents in polymer chains as a function of total conversion using (A) $[\mathrm{Al}]_{0}=10 \mathrm{mM},(\mathrm{B})[\mathrm{Al}]_{0}=20 \mathrm{mM}$, and (C) $[\mathrm{Al}]_{0}$ $=40 \mathrm{mM}:[\mathrm{MA}]_{0}=2.0 \mathrm{M} ;[\mathrm{EBP}]_{0}=20 \mathrm{mM} ;\left[\mathrm{Ru}\left(\mathrm{Cp} * \mathrm{Cl}\left(\mathrm{PPh}_{3}\right)_{2}\right]_{0}=\right.$ $10 \mathrm{mM}$ in toluene/ethanol $(1 / 1, \mathrm{v} / \mathrm{v})$ at $80^{\circ} \mathrm{C}$

an additive (Table 1). With the EBP initiator, RuCp* gave controlled molecular weight, quantitative initiation, and narrower molecular weight distribution (MWD) $\left(M_{\mathrm{w}} / M_{\mathrm{n}}<1.1\right.$ : entry 1 in Table 1), and this polymerization system was based on the optimization of the reaction conditions for polymer preparation.

To optimize the catalyst amount in the polymerization conditions, varying concentrations of RuCp* from 2 to $10 \mathrm{mM}$ were examined using $10 \mathrm{mM} \mathrm{Al}(\mathrm{acac})_{3}$ and $\mathrm{MA}$ was smoothly consumed up to a higher conversion. The higher concentration of $\mathrm{RuCp}^{*}$ showed a fast polymerization rate with linearly increased molecular weight $\left(M_{\mathrm{n}, \mathrm{SEC}}\right)$ and controlled dispersity, suggesting a controlled nature of the LRP (Fig. 2A, C, S3, and $\mathrm{S} 4 \uparrow)$. Further, the effect of $\mathrm{Al}(\mathrm{acac})_{3}$ as an additive was evaluated compared with the absence of the Al cocatalyst $\left(\left[\mathrm{Al}(\mathrm{acac})_{3}\right]_{0}=\right.$ $0 \mathrm{mM})$ and the $(n-\mathrm{Bu})_{3} \mathrm{~N}$ cocatalyzed polymerization system (Fig. 2B and C). In Al cocatalyst, a fast reaction was afforded by keeping controlled MWDs similar to other polymerization conditions, indicating that $\mathrm{Al}(\mathrm{acac})_{3}$ can be considered not only a transesterification catalyst but also an additive for $\mathrm{Ru}^{-}$ catalyzed LRP.

\section{Gradient copolymerization of MA with alcohols via concurrent tandem LRP}

Based on the discussed above, to control the gradient sequence in a polymer chain by concurrent tandem $\mathrm{LRP}, \mathrm{Al}(\mathrm{acac})_{3}$ was used for acrylate-based gradient copolymer synthesis with ethanol. As demonstrated in Fig. 3 (left), for example, the polymerization smoothly proceeded up to higher conversion and ethyl acrylate content (EA) was gradually increased via transesterification in polymerization solution, whereas the MA content slowly decreased by participating in polymerization and transesterification.

Particularly, the rate of polymerization and transesterification depended on the amount of $\mathrm{Al}$ and the reaction temperature (Table 2 and Fig. S5 $\dagger$ ). However, in the case of $[\mathrm{Al}]_{0}$ $=40 \mathrm{mM}$, although the polymerization rate was much faster than the other cases, the initial transesterification rate remained slow, indicating unfavorable to poor control of gradient sequence in the polymer chain.

However, the function of cumulative $\left(F_{\text {cum }}\right)$ contents and instantaneous $\left(F_{\text {inst }}\right)$ contents were good tools for the explaining the composition of gradient sequences in polymer chains. ${ }^{22,27}$ To evaluate the well-controlled gradient sequence in the polymer chain, the $F_{\text {cum }}$ in isolated polymer chains was calculated using ${ }^{1} \mathrm{H}$ NMR (Fig. 3 (right) and Fig. S6-S8†). While the $F_{\text {cum,MA }}$ (solid line) gradually decreased, $F_{\text {cum,EA }}$ gradually increased from 0 to $11 \%$ in the obtained polymer chains. These results indicated that EA generated by transesterification gradually participated in the polymerization; thus, the content of EA in the polymer chain increased. In addition, $F_{\text {inst,EA }}$ (dash line), which represents the differential increasing of $F_{\text {cum,EA }}$, also

Table 2 Effect of $\mathrm{Al}(\mathrm{acac})_{3}$ on the concurrent tandem LRP of MA with $\mathrm{EtOH}^{a}$

\begin{tabular}{llllllll}
\hline Entry & {$[\mathrm{Al}]_{\mathrm{o}}(\mathrm{mM})$} & Temp. $\left({ }^{\circ} \mathrm{C}\right)$ & Time $(\mathrm{h})$ & Conv. $^{b}(\%)$ & $M_{\mathrm{n}}{ }^{c}$ & $M_{\mathrm{w}} / M_{\mathrm{n}}{ }^{c}$ & $F_{\text {cum,MA }} / F_{\text {cum,EA }}{ }^{b}(\% / \%)$ \\
\hline 1 & 10 & 80 & 48 & 66 & 12400 & 1.43 & $89 / 11$ \\
2 & 20 & 40 & 48 & 52 & 10000 & 1.29 & $97 / 3$ \\
3 & 20 & 60 & 48 & 69 & 13400 & 1.24 & $93 / 7$ \\
4 & 20 & 80 & 48 & 82 & 14600 & 1.36 & $89 / 11$ \\
5 & 40 & 80 & 48 & 84 & 10900 & 1.36 & $92 / 8$
\end{tabular}

${ }^{a}[\mathrm{MA}]_{0}=2.0 \mathrm{M} ;[\mathrm{EBP}]_{0}=20 \mathrm{mM} ;\left[\mathrm{RuCp}^{*}\right]_{0}=10 \mathrm{mM}$ in toluene/EtOH $(1 / 1, \mathrm{v} / \mathrm{v})$ at $80{ }^{\circ} \mathrm{C} .{ }^{b}$ Conversion was determined by ${ }^{1} \mathrm{H}$ NMR. ${ }^{c} \mathrm{Measured} \mathrm{by}$ size-exclusion chromatography calibrated with PMMA standards in THF $\left(40{ }^{\circ} \mathrm{C}\right.$, flow rate $\left.0.3 \mathrm{~mL} \mathrm{~min}^{-1}\right)$. 

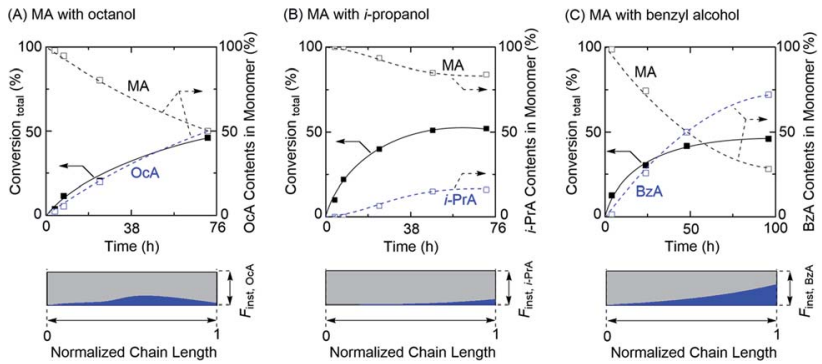

Fig. 4 Gradient copolymerization of MA (top) with (A) octanol, (B) isopropanol, and (C) benzyl alcohol via concurrent tandem LRP and monomer compositions via $F_{\text {inst,RA }}$ in normalized polymer chain (bottom): $[\mathrm{MA}]_{0}=2.0 \mathrm{M} ;[\text { EBP }]_{0}=20 \mathrm{mM} ;[\mathrm{RuCp}]_{0}=10 \mathrm{mM}$; $\left[\mathrm{Al}(\mathrm{acac})_{3}\right]_{0}=20 \mathrm{mM}$ in toluene/alcohols $(1 / 1, \mathrm{v} / \mathrm{v})$ at $80{ }^{\circ} \mathrm{C}$.

gradually increased, with the increasing of the total conversion of monomers from 0 to $67 \%$ indicating that the gradient copolymer was successfully obtained via concurrent tandem LRP. The fairly controlled molecular weight and the narrow MWDs of obtained polymers were observed by SEC analyses (Table 2 and Fig. S9†).

Encouraged by the successful gradient copolymerization of MA with EtOH, the copolymerizations of MA with varying alcohols such as octanol (long alkyl chain), iso-propanol (secondary), and benzyl alcohol were further explored (Fig. 4, Table 3, and Fig. S10-S12†). The MA and the RA newly generated by transesterification in concurrent tandem catalysis participated in polymerization and gave a similar monomer composition pattern in obtained polymer chains. In particular, the well-controlled gradient sequence of BzA in the obtained polymer chain was observed for the polymerization with benzyl alcohol while the polymerization with octanol showed a less controlled gradient sequence of OcA in the product. This likely occurred owing to a long alkyl chain, which might have affected the transesterification efficiency. However, unfortunately, the total monomer conversions of those polymerizations did not reach a high conversion and especially, the polymerization with iso-propanol showed low transesterification efficiency, which lead to a low content of $i$-PrA in the gradient sequence. It can be owing to the lower reactivity of transesterification for the secondary alcohol than that of primary alcohol. Regardless, concurrent tandem polymerization system using $\mathrm{Al}(\mathrm{acac})_{3}$ as an additive for the LRP and as a catalyst for transesterification of the acrylate monomer with varying alcohols provides acrylate-
(A)

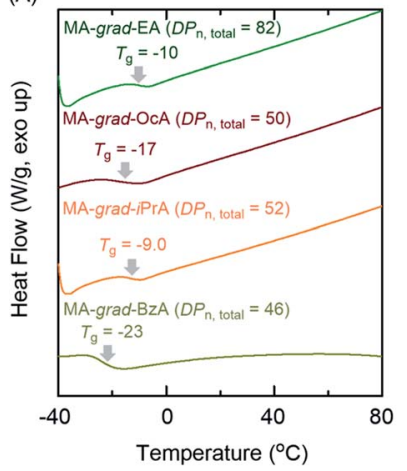

(B)

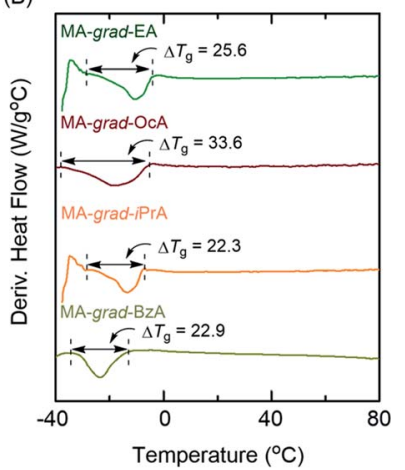

Fig. 5 Extended DSC thermograms $\left(2^{\text {nd }}\right.$ heating process at $10^{\circ} \mathrm{C} \mathrm{min}^{-1}$ after heating up to $120^{\circ} \mathrm{C}$ ) of (A) the obtained gradient copolymers and (B) their differentiated DSC thermograms.

based gradient copolymers, despite the remaining challenges regarding well-controlled gradient sequences in the polymer chain as well as molecular weight control.

We then evaluated the effects of the gradient sequence in the polymer chain on the glass transition behaviors with differential scanning calorimetry (DSC). In general, gradient copolymers have broader phase transition ranges than the corresponding each homopolymers. ${ }^{7,28}$ Here, the obtained gradient copolymers indicated broad glass transition temperatures $\left(T_{\mathrm{g}}\right)$ ranges (Fig. 5) compared with PMA homopolymers $\left(\Delta T_{g}=14.2{ }^{\circ} \mathrm{C}\right.$ for $\mathrm{PMA}_{43}$ and $\Delta T_{g}=14.5{ }^{\circ} \mathrm{C}$ for $\mathrm{PMA}_{100}$ in Fig. S13†). For example, MA-grad-OcA, where the PMA and POcA homopolymers have different $T_{\mathrm{g}} \mathrm{s}$, showed a broad transition in differentiated DSC profiles, supporting that the control of the gradient sequence in the polymer chain successfully occurred $\left(\Delta T_{\mathrm{g}}=33.6^{\circ} \mathrm{C}\right)$. In addition, other series of gradient copolymers exhibited a similarly broader glass transition region, with $\Delta T_{\mathrm{g}}=$ $22-25{ }^{\circ} \mathrm{C}$, than PMA homopolymers, which would be attributed to their gradient sequence controlled polymer chains. These results indicate that $\mathrm{Al}(\mathrm{acac})_{3}$ cocatalyzed concurrent tandem polymerization of MA can successfully provide the acrylatebased gradient copolymers.

\section{Conclusions}

$\mathrm{Al}(\mathrm{acac})_{3}$ was an effective catalyst for the transesterification of MA with various alcohols in the presence of MS $4 \AA$ and separately, it provided good catalysis as a cocatalyst for Ru-catalyzed

Table 3 Gradient copolymerization of MA with varying alcohols via concurrent tandem LRP ${ }^{a}$

\begin{tabular}{lllllll}
\hline Entry & Alcohols & Time $(\mathrm{h})$ & Conv. ${ }^{b}(\%)$ & $M_{\mathrm{n}}{ }^{c}$ & $M_{\mathrm{w}} / M_{\mathrm{n}}{ }^{c}$ & $F_{\text {cum,MA }} / F_{\text {cum,EA }}{ }^{b}(\% / \%)$ \\
\hline 1 & Ethanol & 48 & 82 & 14600 & 1.36 & $89 / 11$ \\
2 & Octanol & 72 & 50 & 14000 & 1.19 & $92 / 8$ \\
3 & iso-Propanol & 72 & 52 & 8000 & 1.34 & $92 / 8$ \\
4 & Benzyl alcohol & 96 & 46 & 14000 & 1.27 & $86 / 24$
\end{tabular}

${ }^{a}[\mathrm{MA}]_{0}=2.0 \mathrm{M} ;[\mathrm{EBP}]_{0}=20 \mathrm{mM} ;[\mathrm{RuCp} *]_{0}=10 \mathrm{mM} ;\left[\mathrm{Al}(\mathrm{acac})_{3}\right]_{0}=20 \mathrm{mM}$ in toluene/alcohols $(1 / 1, \mathrm{v} / \mathrm{v})$ at $80{ }^{\circ} \mathrm{C} .{ }^{b}$ Conversion was determined by ${ }^{1} \mathrm{H}$ NMR. ${ }^{c}$ Measured by size-exclusion chromatography calibrated with PMMA standards in THF $\left(40{ }^{\circ} \mathrm{C}\right.$, flow rate $\left.0.3 \mathrm{~mL} \mathrm{~min}{ }^{-1}\right)$. 
LRP. These two roles of $\mathrm{Al}(\mathrm{acac})_{3}$ for each reaction were successfully synchronized in concurrent tandem LRP, which led the gradient copolymers carrying well-controlled gradient sequences in the polymer chain in one-pot synthesis. Particularly, the monomer library, which was almost limited to the methyl methacrylate type monomers using metal alkoxide catalyzed concurrent tandem LRP, is expanded to the synthesis of acrylate-based gradient copolymers.

\section{Author contributions}

The manuscript was written through the contributions of all authors. All authors have given approval to the final version of the manuscript.

\section{Conflicts of interest}

There are no conflicts to declare.

\section{Acknowledgements}

This work was supported by the Technology Innovation Program (No. 20011123) funded By the Ministry of Trade, industry \& Energy (MI, Korea), Korea Research Institute of Chemical Technology (KRICT) (No. KS2041-00) and the National Research Foundation of Korea (NRF) grant funded by the Korea government (No. 2021R1I1A3042146).

\section{References}

1 F. E. Bailey, D. W. C. Von, M. Matzner, R. H. Young and L. M. Robeson, Gradient polymers of two or more alpha mono-olefinic monomers capable of polymerizing with themselves and each other, US Pat.US4065520A, 1977.

2 S. Jouenne, J. A. Gonzalez-Leon, A.-V. Ruzette, P. Lodefier, S. Tence-Girault and L. Leibler, Styrene/butadiene gradient block copolymers: molecular and mesoscopic structures, Macromolecules, 2007, 40, 2432-2442.

3 S. Datta, A. r. Jutková, P. Šrámková, L. Lenkavská, V. Huntošová, D. a. Chorvát, P. Miškovský, D. Jancura and J. Kronek, Unravelling the excellent chemical stability and bioavailability of solvent responsive curcumin-loaded 2ethyl-2-oxazoline-grad-2-(4-dodecyloxyphenyl)-2-oxazoline copolymer nanoparticles for drug delivery, Biomacromolecules, 2018, 19, 2459-2471.

4 Y. Luo, Y. Guo, X. Gao, B. G. Li and T. Xie, A general approach towards thermoplastic multishape-memory polymers via sequence structure design, Adv. Mater., 2013, 25, 743-748.

5 S. B. Lee, A. J. Russell and K. Matyjaszewski, ATRP Synthesis of Amphiphilic Random, Gradient, and Block Copolymers of 2-(Dimethylamino)ethyl Methacrylate and n-Butyl Methacrylate in Aqueous Media, Biomacromolecules, 2003, 4, 1386-1393.

6 E. Vlassi and S. Pispas, Solution behavior of hydrolyzed gradient methyl/phenyl oxazoline copolymers and complexation with DNA, Macromol. Chem. Phys., 2015, 216, 873-883.
7 J. Kim, M. M. Mok, R. W. Sandoval, D. J. Woo and J. M. Torkelson, Uniquely broad glass transition temperatures of gradient copolymers relative to random and block copolymers containing repulsive comonomers, Macromolecules, 2006, 39, 6152-6160.

8 C. J. Hawker, A. W. Bosman and E. Harth, New polymer synthesis by nitroxide mediated living radical polymerizations, Chem. Rev., 2001, 101, 3661-3688.

9 V. Sciannamea, R. Jérôme and C. Detrembleur, In-situ nitroxide-mediated radical polymerization (NMP) processes: their understanding and optimization, Chem. Rev., 2008, 108, 1104-1126.

10 T. Ribaut, P. Lacroix-Desmazes, B. Fournel and S. Sarrade, Synthesis of gradient copolymers with complexing groups by RAFT polymerization and their solubility in supercritical $\mathrm{CO}_{2}$, J. Polym. Sci., Part A: Polym. Chem., 2009, 47, 5448-5460.

11 S. Perrier and P. Takolpuckdee, Macromolecular design via reversible addition-fragmentation chain transfer (RAFT)/ xanthates (MADIX) polymerization, J. Polym. Sci., Part A: Polym. Chem., 2005, 43, 5347-5393.

12 G. Moad, E. Rizzardo and S. H. Thang, Radical additionfragmentation chemistry in polymer synthesis, Polymer, 2008, 49, 1079-1131.

13 M. Kamigaito, T. Ando and M. Sawamoto, Metal-catalyzed living radical polymerization, Chem. Rev., 2001, 101, 36893746.

14 M. Ouchi, T. Terashima and M. Sawamoto, Transition metalcatalyzed living radical polymerization: toward perfection in catalysis and precision polymer synthesis, Chem. Rev., 2009, 109, 4963-5050.

15 K. Matyjaszewski and J. Xia, Atom transfer radical polymerization, Chem. Rev., 2001, 101, 2921-2990.

16 N. V. Tsarevsky and K. Matyjaszewski, "Green” atom transfer radical polymerization: from process design to preparation of well-Defined environmentally friendly polymeric materials, Chem. Rev., 2007, 107, 2270-2299.

17 R. Whitfield, K. Parkatzidis, M. Rolland, N. P. Truong and A. Anastasaki, Tuning Dispersity by Photoinduced Atom Transfer Radical Polymerisation: Monomodal Distributions with ppm Copper Concentration, Angew. Chem., Int. Ed., 2019, 58, 13323-13328.

18 M. Rolland, N. P. Truong, R. Whitfield and A. Anastasaki, Tailoring Polymer Dispersity in Photoinduced IronCatalyzed ATRP, ACS Macro Lett., 2020, 9, 459-463.

19 M. Rolland, V. Lohmann, R. Whitfield, N. P. Truong and A. Anastasaki, Understanding dispersity control in photoatom transfer radical polymerization: Effect of degree of polymerization and kinetic evaluation, J. Polym. Sci., 2021, DOI: 10.1002/pol.20210319.

20 K. Nakatani, T. Terashima and M. Sawamoto, Concurrent tandem living radical polymerization: gradient copolymers via in situ monomer transformation with alcohols, J. Am. Chem. Soc., 2009, 131, 13600-13601.

21 J. Ueda, M. Matsuyama, M. Kamigaito and M. Sawamoto, Multifunctional initiators for the ruthenium-mediated living radical polymerization of methyl methacrylate: Di- 
and trifunctional dichloroacetates for synthesis of multiarmed polymers, Macromolecules, 1998, 31, 557-562.

22 K. Nakatani, Y. Ogura, Y. Koda, T. Terashima and M. Sawamoto, Sequence-regulated copolymers via tandem catalysis of living radical polymerization and in situ transesterification, J. Am. Chem. Soc., 2012, 134, 4373-4383.

23 Y. Ogura, T. Terashima and M. Sawamoto, Synthesis of fluorinated gradient copolymers via in situ transesterification with fluoroalcohols in tandem living radical polymerization, Polym. Chem., 2017, 8, 2299-2308.

24 Y. Watanabe, T. Ando, M. Kamigaito and M. Sawamoto, Ru $\left.(\mathrm{Cp})^{*}\right) \mathrm{Cl}\left(\mathrm{PPh}_{3}\right)_{2}$ : A versatile catalyst for living radical polymerization of methacrylates, acrylates, and styrene, Macromolecules, 2001, 34, 4370-4374.

25 H. Takahashi, T. Ando, M. Kamigaito and M. Sawamoto, $\mathrm{RuH}_{2}\left(\mathrm{PPh}_{3}\right)_{4}:$ An active catalyst for living radical polymerization of methyl methacrylate at or above room temperature, Macromolecules, 1999, 32, 6461-6465.

26 H. Takahashi, T. Ando, M. Kamigaito and M. Sawamoto, Half-metallocene-type ruthenium complexes as active catalysts for living radical polymerization of methyl methacrylate and styrene, Macromolecules, 1999, 32, 38203823.

27 X. Gu, L. Zhang, Y. Li, W. Zhang, J. Zhu, Z. Zhang and X. Zhu, Facile synthesis of advanced gradient polymers with sequence control using furan-protected maleimide as a comonomer, Polym. Chem., 2018, 9, 1571-1576.

28 M. D. Lefebvre, M. Olvera de la Cruz and K. R. Shull, Phase Segregation in Gradient Copolymer Melts, Macromolecules, 2004, 37, 1118-1123. 